\title{
Influence of flow conditions on the distribution of thermal stresses in the waterwall tubes connected by fins
}

\author{
Marek Majdak ${ }^{*}$ \\ Department of Energy, Cracow University of Technology, al. Jana Pawla II 37, 31-864 Cracow, Poland
}

\begin{abstract}
In this study are presented results of numerical analysis of the thermal conditions of smooth waterwall tubes connected by fins and heated with equal heat flux. Inside tubes flows the water at supercritical parameters. The thermodynamic parameters at the inlet to each tube are similar but the mass flow of the fluid differs in each tube. Numerical model used for analysis allows to determine the temperature distribution, in online mode, in every control element of the analysed tubes and in the finite elements of the working fluid depending on the current thermodynamic parameters of the fluid and tubes. After calculation of the temperature distribution field, it can be used to determine the thermal stresses distribution in tubes and fins and determine the parts of elements, where the maximum values of the thermal stresses occur. The presented analysis was carried out for comparison of the thermal stresses distribution in small fragment of the combustion chamber wall in case of changing the fluid mass flows in neighbouring waterwall tubes.
\end{abstract}

\section{Introduction}

Due to necessity of development of more efficient and environmental-friendly technologies of energy production in huge power plants were introduced the supercritical boilers. Unfortunately, the thermal conditions occurring in the combustion chambers of supercritical boilers are much more complicated than in the subcritical boilers. The heat flux and mass flow of the working fluid (working fluid is generally a supercritical steam) varies in the width of the combustion chamber wall. Therefore it is necessary to develop algorithms that allows to determine temperature and thermal stresses distribution in cross-sections of the waterwall tubes and fins between them. In this paper will be presented the method of calculations of temperature distribution in multiple waterwall tubes connected by fins in case of the equal heating of each tube and different mass flows of fluid inside the tubes. The temperature field obtained by using this algorithm can be used to calculation of the thermal stresses distribution in cross-sections of the analysed system.

\section{Problem analysis}

In the article are presented temperature and thermal stress distributions in combined waterwall tubes, which are a fragment of the wall of combustion chamber in supercritical boiler. The developed model allows to calculate fluid and wall thermal parameters in each time step and in each control volume. The water parameters are calculated using the IAPWS IF97 table [1], for calculation of wall metal parameters are used producers data for steel $16 \mathrm{Mo} 3$.
The purpose of developed model was to extend the functionality of the model presented in [2] to allow the simultaneous simulation of the temperature distribution in multiple combined tubes, in which are flowing fluids with different mass flow values. For the purpose of this paper the temperature and thermal stress distributions will be presented for two waterwall tubes connected by fins, but the model's construction allows for analysis of much more complex cases.

In order to perform calculations using proposed model were used balance equations of energy (1), momentum (2) and mass (3), which can be written as follows [3-4]:

- Energy balance must be analysed as a comparison of the heat transfer, internal energy and kinetic energy of the fluid inside the control volume. Energy balance equation can be written as:

$$
\partial h / \partial z=(\rho A / \dot{m}) *\left\{(-\partial h / \partial \tau)+\left[4 \alpha(\theta-t) /\left(d_{\mathrm{w} \rho} \rho\right)\right]\right\}
$$

- To write the momentum balance equation, we must take into account momentum flux flowing inside and outside of the analysed control volume, changes of the momentum accumulated in the control volume and all forces affecting this volume. The momentum balance equation can be written as:

$$
\partial / \partial z\left[m^{2} /\left(A^{2} \rho\right)+p\right]=-(1 / A) *(\partial \dot{m} / \partial \tau)-\left(\partial p_{\mathrm{t}} / \partial z\right)-\rho g \sin \beta
$$
)

- Mass balance equation can be written as:

$$
\partial \dot{m} / \partial z=-A^{*}(\partial p / \partial \tau)
$$

In order to build the numerical model above equations (1-3) were solved using the backward

\footnotetext{
* Corresponding author: marek.majdak@.pk.edu.pl
} 
difference quotients which replaced the time derivatives on the right side of equations. The temperature distribution has been developed using the extended version of the division of the cross-section of waterwall tube, presented in [5], which is shown in the Fig. 1.

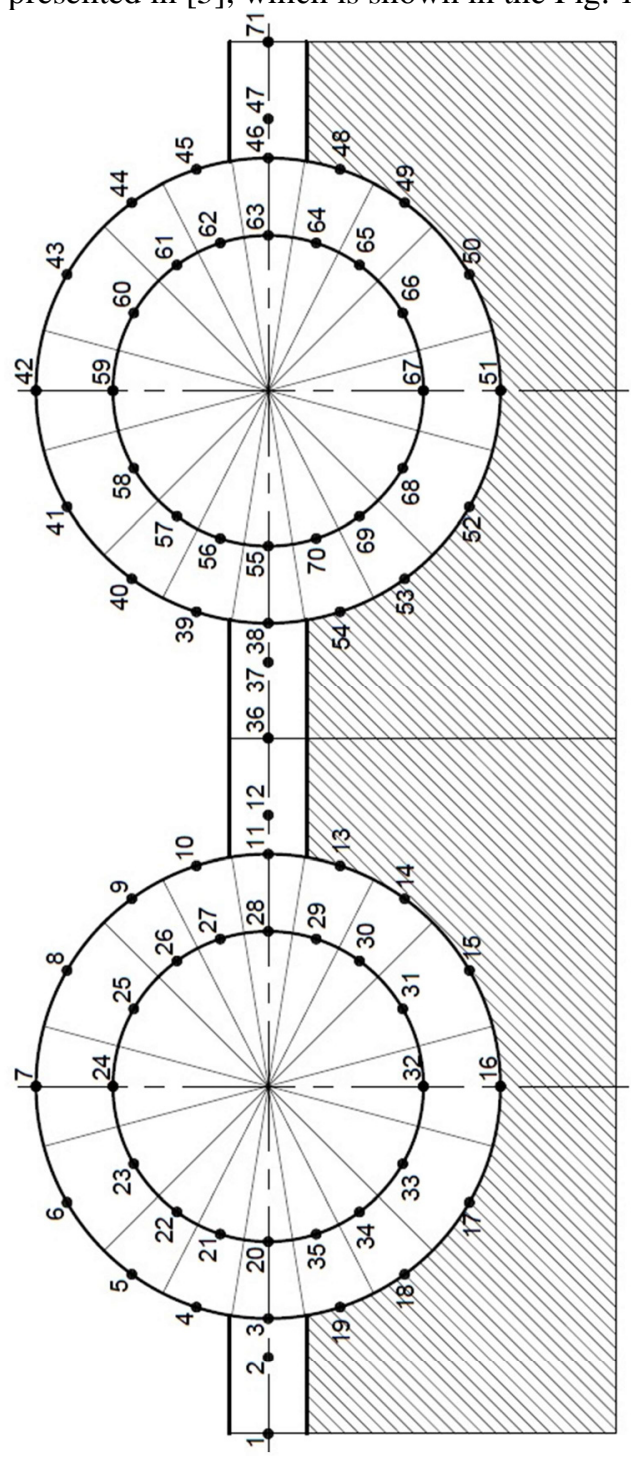

Fig. 1. Division of the analysed system for the control areas and numbering of selected characteristic points.

The temperature distribution in tubes and fins in the cross-section of analysed model presented in Fig. 1 can be calculated, for example for point 36 , by using formula as follows:

$$
\begin{gathered}
c_{36, \mathrm{j}} v_{36, \mathrm{j}} \Delta x \delta_{\mathrm{w}} \Delta z=\lambda_{36, \mathrm{j}}\left[\left(\theta_{12, \mathrm{j}}-\theta_{36, \mathrm{j}}\right) / \Delta x\right] \delta_{\mathrm{w}} \Delta z \\
+\lambda_{36, \mathrm{j}}\left[\left(\theta_{37, \mathrm{j}-} \theta_{36, \mathrm{j}}\right) / \Delta x\right] \delta_{\mathrm{w}} \Delta z+\lambda_{36, j} \delta_{\mathrm{w}} \Delta x\left[\left(\theta_{36, \mathrm{j}+1^{-}} \theta_{36, \mathrm{j}}\right) / \Delta z\right] \\
+\lambda_{36, \mathrm{j}} \delta_{\mathrm{w}} \Delta x\left[\left(\theta_{36, \mathrm{j}-1^{-}} \theta_{36, \mathrm{j}}\right) / \Delta z\right]+q_{36, \mathrm{j}} \Delta x \Delta z
\end{gathered}
$$

As the input data for the proposed model were used thermal parameters of working fluid from one of the Polish supercritical power plants. In order to compare temperature distribution and thermal stresses distribution, were presented the results of two analysed cases - in first case the fluid mass flow in both tubes is equal, in second one the fluid flow in one tube is lowered by $25 \%$ in relation to the reference value.
The most important information about analysed

\begin{tabular}{|c|c|}
\hline Parameter & Nominal value \\
\hline Mass flow per tube & $1 \mathrm{~kg} / \mathrm{s}$ \\
\hline $\begin{array}{l}\text { Fluid pressure at the inlet to the } \\
\text { tube }\end{array}$ & $30 \mathrm{MPa}$ \\
\hline $\begin{array}{l}\text { Fluid temperature at the inlet to } \\
\text { the tube }\end{array}$ & $350^{\circ} \mathrm{C}$ \\
\hline Length of tubes & $90 \mathrm{~m}$ \\
\hline $\begin{array}{l}\text { Tube outer diameter } \times \text { wall } \\
\text { thickness }\end{array}$ & $51 \times 5 \mathrm{~mm}$ \\
\hline Fin thickness & $5 \mathrm{~mm}$ \\
\hline Angle of inclination of tubes & $25^{\circ}$ \\
\hline Heat flux & $50 \mathrm{~kW} / \mathrm{m} 2$ \\
\hline Tube pitch & $75 \mathrm{~mm}$ \\
\hline Material for tubes and fins & $16 \mathrm{Mo} 3$ steel \\
\hline
\end{tabular}
tubes are presented in Table 1:

Table 1. Operating conditions in analysed system.

\section{Results and discussion}

To present the possibilities of the proposed model the simulations were carried on two cases: with equal mass flows of the fluid flowing inside both tubes and with the mass flow in one tube decreased by $25 \%$ in reference to the nominal mass flow value. After calculations performed using MATLAB code, the temperature distribution field has been exported into the worksheet and used as a input data for the CFD model, which allows to calculate the thermal stress distribution.

To compare the results obtained in two analysed cases the temperature distributions in the cross-section at $60 \mathrm{~m}$ from the inlets to tubes were presented on Fig. 2 - Fig. 3. 


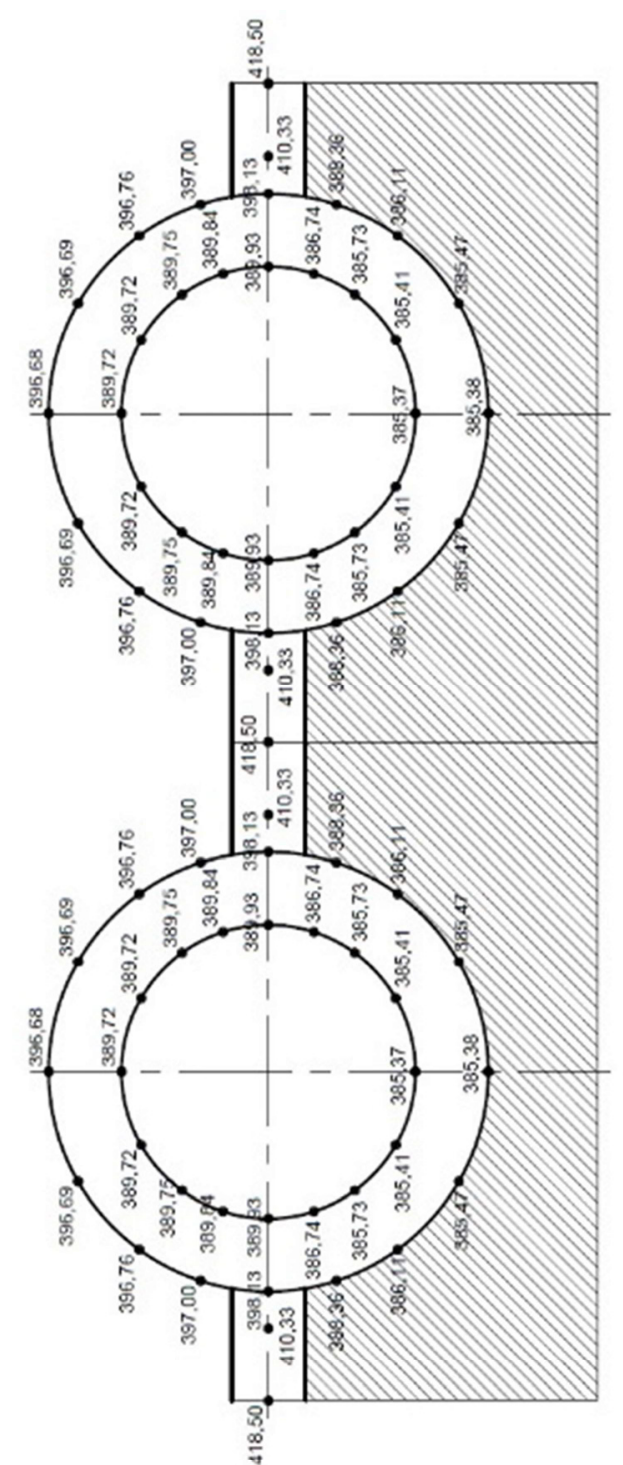

Fig. 2. Temperature distribution of the cross-section of the system at $60 \mathrm{~m}$ from the inlets to tubes in case of equal mass flow of the fluid flowing inside each tube.

The temperature distribution obtained in this case is symmetrical, the highest temperature values, $418,50{ }^{\circ} \mathrm{C}$, are obtained in the middle of fins. The temperature values in the middle of the external side of front walls of both tubes are $396,68^{\circ} \mathrm{C}$.

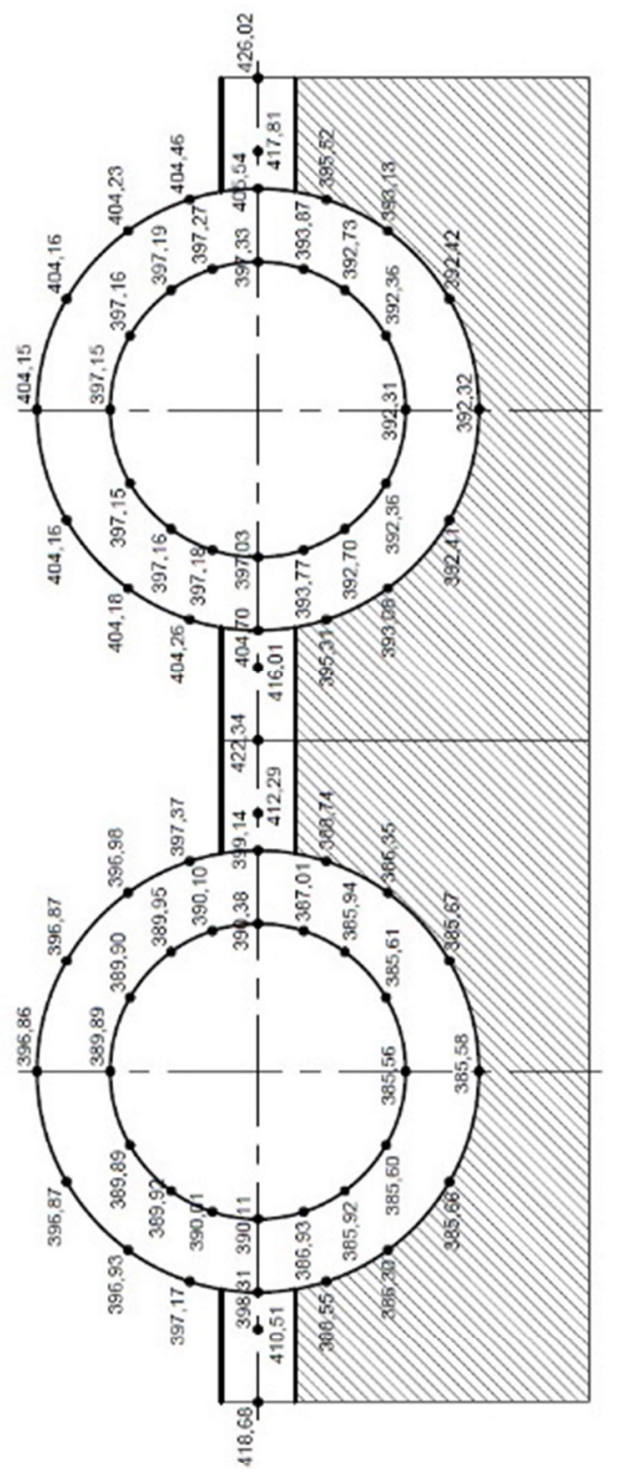

Fig. 3. Temperature distribution of the cross-section of the system at $60 \mathrm{~m}$ from the inlets to tubes in case of decreasing the mass flow of the fluid flowing in right tube by $25 \%$ (in reference to nominal value).

The temperature distribution obtained in the case in which the mass flow in the right tube is decreased by $25 \%$ is unsymmetrical, higher temperature values are obtained in the cross-section of right tube - in results from the lower fluid mass flow inside this tube. The temperature in the middle of fin between tubes equals to $422,34{ }^{\circ} \mathrm{C}$, the temperature values in the middle of the external side of front walls of both tubes are $396,86^{\circ} \mathrm{C}$ for the left tube and $404,15^{\circ} \mathrm{C}$ for the right tube.

In the following figures (Fig. 4 - Fig. 5) are presented thermal stress distributions in the selected cross-section calculated using ANSYS software on the base of temperature distributions obtained from the proposed numerical model. As expected, the more varied is the temperature distribution, the higher thermal stress values are obtained. 


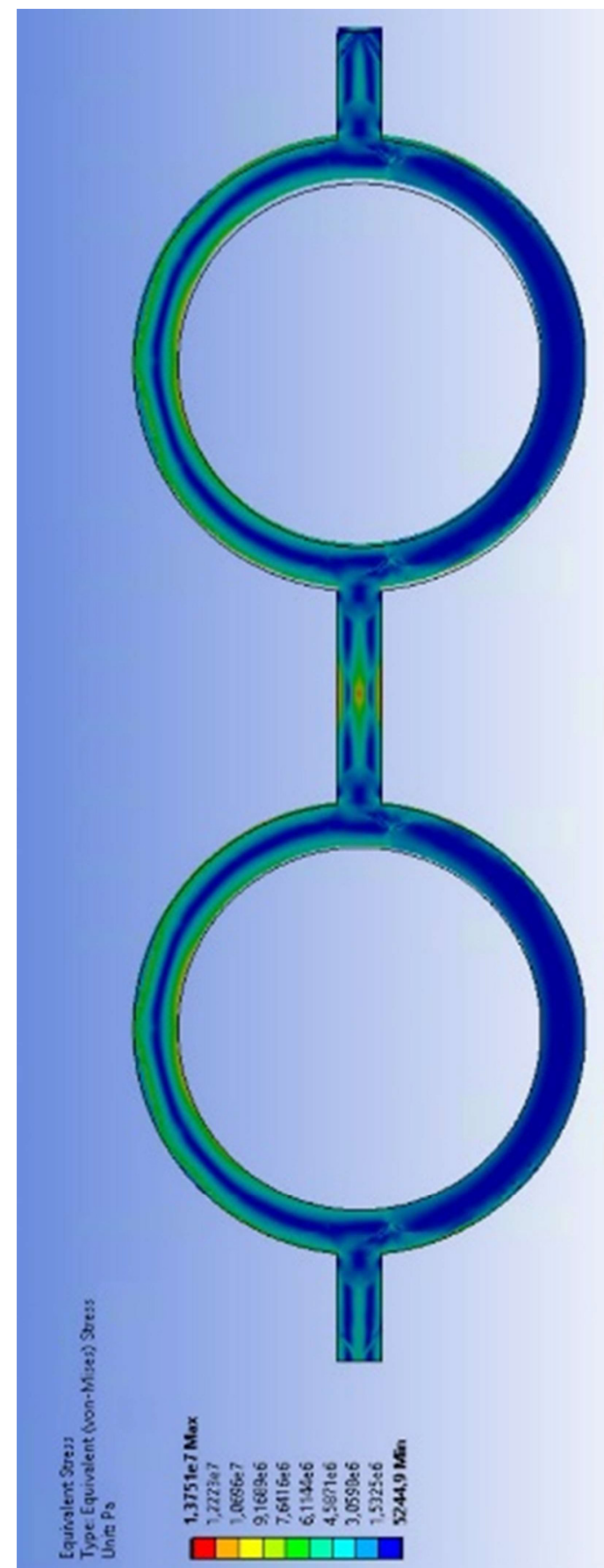

Fig. 4. Thermal stresses distribution of the cross-section of the system at $60 \mathrm{~m}$ from the inlets to tubes in case of equal mass flow of the fluid flowing inside each tube.

The thermal stress distribution resulting from the symmetrical temperature distribution is also symmetrical. The highest thermal stress value occurs in the middle of the fin between tubes and equals to $13,75 \mathrm{MPa}$. The highest thermal stresses in tubes occur in the front walls of tubes and equal to about $10,7 \mathrm{MPa}$ - they results from the high gradient of temperature on the thickness of the wall.

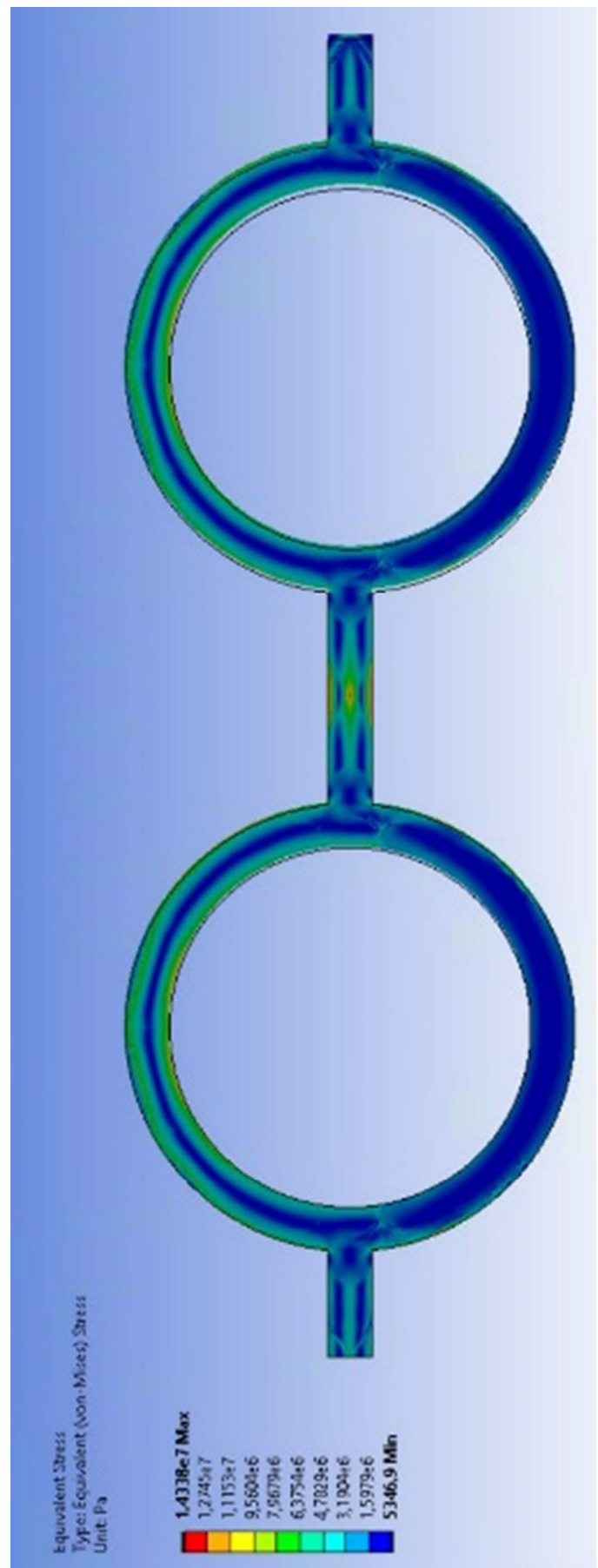

Fig. 5. Thermal stresses distribution of the cross-section of the system at $60 \mathrm{~m}$ from the inlets to tubes in case of decreasing the mass flow of the fluid flowing in right tube by $25 \%$ (in reference to nominal value).

The thermal stress distribution resulting from the temperature distribution in second analysed case is unsymmetrical, higher thermal stress values occur in the left tube. The highest thermal stress value occurs in the middle of the fin between tubes and equals to 14,34 MPa. The highest thermal stresses in tubes occur in the front walls of tubes and equal to about $11,15 \mathrm{MPa}$ for the left tube and about 10,50 MPa for the right tube - they results from the high gradients of temperature on the thickness of the walls. 


\section{Conclusions}

In the article was presented a new model of determining thermal stresses distribution in tubes in which flows working fluid with the different mass flow in each tube. The proposed algorithm allows calculating thermodynamic parameters of working fluid and wall material for each time step and each control volume of analysed model. By using this model, it is possible to calculate temperature values in 36 characteristic points of the cross-section of each tube connected with fins. Obtained temperature values are close to the temperature distributions obtained in other scientific papers.

The novelty of the model is the possibility of simultaneous simulation of heat exchange in many waterwall tubes when a working fluid with a different mass flow flows in each tube. The structure of the proposed model allows to perform the analysis for more than two tubes, so it is possible to perform calculations for a much more complex cases than shown in the article.

Obtained temperature distribution fields can be used as input data for simulation of thermal stress distribution. By using this model the temperature and thermal stress distributions in the walls of the combustion chambers can be calculated and the places where the highest thermal stress values occur can be determinated. The determination of the thermal stress distribution is very important in supercritical boilers because it can provide a data needed to redesign parts of the combustion chamber in which the highest thermal stresses occur.

\section{References}

1. W. Wagner, J. R. Cooper, A. Dittmann, J. Kijima, H.-J. Kretzschmar, A. Kruse, R. Mareš, K.

Oguchi, H. Sato, I. Stöcker, O. Šifner, Y. Takaishi, I. Tanishita, J. Trübenbach, Th. Willkommen, J.

Eng. Gas Turbines Power 122, 150-182 (2000)

2. M. Majdak, E3S Web Conf. 128, 01024 (2019)

3. S. Grądziel, K. Majewski, Chem Process Eng 37(2), 199-213 (2016)

4. M. Majdak, S. Grądziel, Energy 209, 118416 (2020)

5. M. Majdak, S. Grądziel, Therm. Sci. 23(4), 13331344 (2019) 